EXTENDED REPORT

\title{
Long term effect on IOP of a stainless steel glaucoma drainage implant (Ex-PRESS) in combined surgery with phacoemulsification
}

\author{
C E Traverso, F De Feo, A Messas-Kaplan, P Denis, S Levartovsky, E Sellem, F Badalà, Z Zagorski, \\ A Bron, M Belkin
}

Br J Ophthalmol 2005;89:425-429. doi: 10.1136/bjo.2004.058032

See end of article for authors' affiliations

Correspondence to:

Professor Carlo E Traverso,

Department of

Neurosciences,

Ophthalmology and

Genetics, University of

Genova, Italy;

mc8620@mclink.it

Accepted for publication

1 December 2004

\begin{abstract}
Aim: To evaluate the efficacy and safety of a stainless steel miniature glaucoma drainage device (Ex-PRESS R50) for the surgical treatment of primary open angle glaucoma (POAG) and cataract when combined with phacoemulsification.

Methods: Clinical, prospective, multicentre, single treatment arm, non-randomised, non-masked study. The Ex-PRESS device was implanted at the limbus under a conjunctival flap. Phacoemulsification cataract extraction and in the bag $\mathrm{IOL}$ implantation were performed through clear cornea temporally. Primary outcome: IOP change; secondary outcomes: side effects and VA changes.

Results: 26 eyes of 25 patients were implanted with the device. The mean (SD) follow up was 23.9 (10.4) months and the mean age was 75.1 (7.1) years. 17/26 eyes have more than 3 years of follow up. One case was discontinued because of device removal, one because of death, and three were lost to follow up. Efficacy: preoperative IOP was 21 (4) $\mathrm{mm} \mathrm{Hg}$; at 1, 2, and 3 years IOP was 15.3 (3.1) $\mathrm{mm} \mathrm{Hg}(35 \%$ reduction), 16.6 (2.7) $\mathrm{mm} \mathrm{Hg}$ (29\% reduction), and 16 (2.6) mm Hg (22\% reduction) respectively. KaplanMeyer determined overall success rate (IOP $\leqslant 21 \mathrm{~mm} \mathrm{Hg}$ at the last visit with or without medications) as $76.9 \%$. The number of antiglaucoma medications was reduced by $95 \%$ at year 1 . Only six patients $(23 \%)$ were taking IOP lowering treatment at their last visit, five with one medication and one with two medications. Side effects: early postoperative complications were clinically mild and included six cases of hypotony (IOP $<5 \mathrm{~mm} \mathrm{Hg}$ ), three cases of hyphaema $(<2 \mathrm{~mm}$ ) with no clinically significant further effects. Long term complications were two cases $(7.7 \%)$ of device rotation (one treated by reposition) and three cases (11.5\%) of conjunctival erosion at 2 and 3 years.

Conclusions: The Ex-PRESS implant, combined with phacoemulsification cataract extraction, is clinically safe and effective, maintaining in the long term a large reduction in IOP and in the number of antiglaucoma medications.
\end{abstract}

T he occurrence of both glaucoma and clinically relevant cataract in the same individual is a frequent condition, especially in the elderly population. Besides age, this might be related to the possible role of antiglaucoma medications in the progression of lens opacity. ${ }^{1-3}$ When both procedures are required, these can be performed separately or in combination.

Glaucoma filtering surgery is indicated when glaucomatous damage progresses despite the lower level of intraocular pressure (IOP) obtained with pharmacological and/or laser treatment. In the past few years, filtering surgery has improved, with an increased likelihood of successfully lowering the IOP while minimising complications. While full thickness filtration procedures considerably reduced the IOP, they were associated with early postoperative hypotony and related side effects and became progressively less popular.

Trabeculectomy has been the surgical treatment of choice for primary open angle glaucoma (POAG) since the $1970 \mathrm{~s}^{4}$; its success rates and complication however are less than ideal. $^{56}$ Early hypotony and bleb infections are still of concern. ${ }^{7-13}$

Glaucoma drainage implants, designed to shunt the aqueous posteriorly, represent an alternative method for lowering IOP in glaucomatous patients, ${ }^{14-17}$ commonly used in refractory glaucoma or after the failure of other surgical approaches.

The Ex-PRESS is a miniature stainless steel glaucoma device, developed as an alternative to trabeculectomy and to the other types of glaucoma filtering surgery for patients with POAG. This procedure would be theoretically more reproducible and simple to perform as well as less traumatic to the ocular tissue than traditional filtering surgery. The implant is inserted at the limbus under a conjunctival flap and diverts the aqueous humour from the anterior chamber to the subconjunctival space, obtaining the formation of a conjunctival filtration bleb, in a similar way to trabeculectomy. This procedure can be performed on its own or in combination with phacoemulsification.

This study is about the long term efficacy and safety results of the Ex-PRESS device (Optonol Ltd) implanted for the surgical treatment of POAG and cataract when combined with phacoemulsification.

\section{PATIENTS AND METHODS}

This non-randomised, multicentre, prospective trial was conduced at three different centres. All operations were performed by one experienced ophthalmic surgeon in each centre. Surgeons were instructed in the implantation procedure for the device and practised the procedure on animal eyes before operating on humans. Approval from the institutional review boards was obtained. After receiving a comprehensive explanation of the experimental nature of

Abbreviations: 5-FU, 5-fluorouracil; CRF, case report forms; IOL, intraocular lens; IOP, intraocular pressure; POAG, primary open angle glaucoma 
this procedure, informed consent was obtained from each patient.

Patients were recruited prospectively and non-consecutively. Their mean age was 75.1 (SD 7.1) years. Eligibility criteria included the presence of POAG, mobile unscarred conjunctiva for at least two clock hours superiorly, an indication for glaucoma filtering surgery based on uncontrolled IOP despite medications, and the presence of a clinically significant decrease of visual acuity as a result of cataract. Eyes with angle closure glaucoma, neovascular glaucoma, congenital or juvenile glaucoma, or monocular patients were excluded. All patients had visual field examinations within 6 months before the recruitment, and were affected by POAG.

Upon enrolment each patient underwent a complete ophthalmic examination; postoperative evaluations were performed on the first and seventh days and on the first, second, third, sixth, ninth, 12th, 18th, 24th, 30th, 36th, 42nd, and 48th postoperative months, or more often when required. The examination consisted of measurement of best corrected visual acuity, slit lamp biomicroscopy of the anterior and posterior segments, IOP measurement by applanation tonometry, and gonioscopy. History and all medication details were recorded. Standard case report forms (CRF) were used.

The Ex-PRESS R50 drainage device is an non-valved flow restricting implant, made of implantable stainless steel (316L), which is approved for medical and ophthalmic applications. The R50 device is built with a $3 \mathrm{~mm}$ long tube with a $400 \mu \mathrm{m}$ (27 gauge) external diameter, a $50 \mu \mathrm{m}$ inner diameter, and a bevelled, sharpened, rounded tip (fig 1). The disc-like flange at the device's proximal end prevents it being implanted too deeply, while the spur-like projection prevents its extrusion. The external flange and inner spur are angled to conform to the anatomy of the sclera, and the distance between them corresponds to the scleral thickness at the limbus, where the device is implanted. Three holes around the proximal end of the device's shaft ensure filtration if the main orifice becomes blocked by the iris or other tissues.

\section{Surgical technique}

The Ex-PRESS R50 device was implanted under local or topical anaesthesia, using standard ophthalmic microsurgical instruments. The procedure consisted of a 2-4 mm circumferential conjunctiva opening, $10-15 \mathrm{~mm}$ posterior to the limbus. The implant, mounted on its introducer, was slid under the conjunctiva and Tenon's capsule and implanted radial to the limbus and parallel to the iris through a preincision performed with a 27 gauge needle. The introducer was then withdrawn. The conjunctiva was closed with a suture at the surgeon's discretion. Manipulation of the conjunctiva during the introduction was limited to one or two clock hours. At the end of this procedure, a temporal

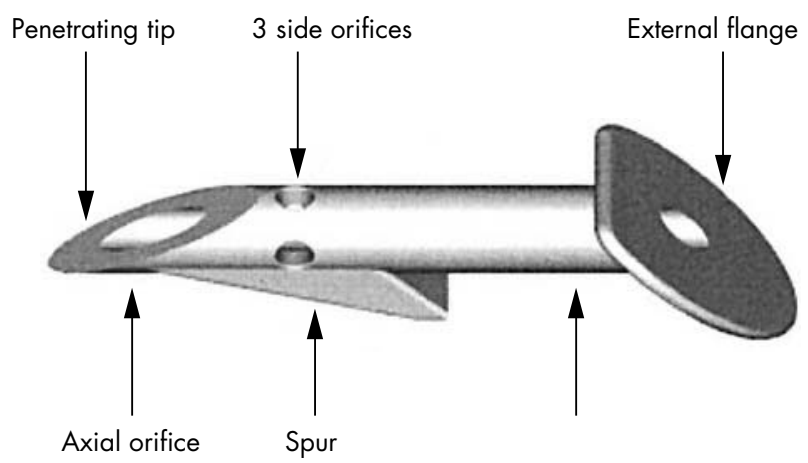

Figure 1 Design of the Ex-PRESS miniature glaucoma implant.

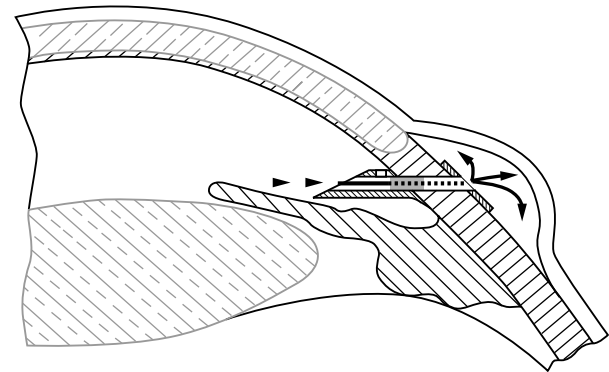

Figure 2 Schematic drawing of the Ex-PRESS implant in situ.

clear cornea phacoemulsification cataract extraction with "in the bag" intraocular lens (IOL) insertion was performed. (A diagrammatic representation of the implant in place is shown in fig 2.)

CRF were used to collect data on the procedure, its duration, and any complications during surgery. Using a semiquantitative scale of $1-5$ (where $1=$ very easy or very well positioned and $5=$ very difficult or very poorly positioned), the surgeon graded the ease of the insertion and positioning of the implant at the limbus. At each follow up, the surgeon carried out a complete ophthalmic examination, recording all data on the CRF, including anterior chamber depth, device position, presence or absence of the bleb, and visual acuity. The IOP and the use of antiglaucoma medications or other IOP reduction procedures during the follow up were primary outcome measures. Secondary outcome measures included the visual acuity and the occurrence of perioperative or postoperative complications.

The procedure was labelled an overall success when IOP was $<21 \mathrm{~mm} \mathrm{Hg}$ with or without antiglaucoma medications; a complete success was defined as an IOP $<21 \mathrm{~mm} \mathrm{Hg}$ without medications. Postoperative bleb management and scarring modulation with needling or 5-fluorouracil (5-FU) injections were not a criterion for failure.

Results were analysed on an "intent to treat" basis. Data were presented as mean (SD), unless otherwise specified. The Wilcoxon signed rank test was used to compare changes from baseline IOP and to compare the number of antiglaucoma medications used by the patient. Time to failure, defined as an IOP $>21 \mathrm{~mm} \mathrm{Hg}$ at two consecutive visits, IOP $>21 \mathrm{~mm} \mathrm{Hg}$ at the last visit, or a need for additional surgery, was evaluated using Kaplan-Meyer survival analysis. A p value of $<0.05$ was considered statistically significant for all analyses. Statistical analyses were carried out using the SPSS statistical package or Microsoft Excel.

\section{RESULTS}

The Ex-PRESS R50 device was implanted into 26 eyes of 25 white patients with POAG and cataract. The mean age of the patients was 75.1 (7.1) years; table 1 details other demographic data.

The mean follow up period was 30.2 (14.5) months. Twenty five patients completed 1 year, 18 patients 2 years,

Table 1 Patients and methods

Patients

Number of eyes

Female $15(57.7 \%$

Age (SD) (years)

Types of glaucoma

Primary open angle glaucoma

Pseudoexfoliative glaucoma

Ocular hypertension

26

Male $11(42.3 \%)$

75.1 (7.1)

$20(76.9 \%)$

$5(19.2 \%)$

$1(3.9 \%)$ 
Table 2 Efficacy-IOP summary, long term

\begin{tabular}{|c|c|c|c|c|c|c|}
\hline & \multirow[b]{2}{*}{ No } & \multicolumn{5}{|c|}{ IOP $(\mathrm{mm} \mathrm{Hg})$} \\
\hline & & Mean & SD & Median & Min & Max \\
\hline Before & 26 & 24.5 & 5.0 & 24 & 17 & 40 \\
\hline 1st year & 25 & 15.3 & 3.1 & 15 & 7 & 22 \\
\hline 2nd year & 18 & 16.7 & 2.7 & 17 & 13 & 25 \\
\hline $3 r d$ year & 9 & 18.6 & 5.1 & 17 & 13 & 28 \\
\hline 4th year & 4 & 16 & 6.9 & 18 & 6 & 22 \\
\hline
\end{tabular}

\begin{tabular}{|c|c|c|}
\hline Target IOP & Overall success (with or without meds) & Complete success (without meds) \\
\hline \multicolumn{3}{|c|}{ Success rate at 2 years $(n=18)$} \\
\hline$\leqslant 21 \mathrm{~mm} \mathrm{Hg}$ & $17 / 18(94.4 \%)$ & $12 / 18(66.7 \%)$ \\
\hline$\leqslant 18 \mathrm{~mm} \mathrm{Hg}$ & $16 / 18(88.9 \%)$ & $11 / 18(61.1 \%)$ \\
\hline \multicolumn{3}{|c|}{ Success rate at last visit ( $n=26$ ) } \\
\hline$\leqslant 21 \mathrm{~mm} \mathrm{Hg}$ & $20 / 26(76.9 \%)$ & $17 / 26(65.4 \%)$ \\
\hline$\leqslant 18 \mathrm{~mm} \mathrm{Hg}$ & 19/26 (73.1\%) & $16 / 26(61.5 \%)$ \\
\hline
\end{tabular}

nine patients 3 years, and four patients 4 years. Two subjects discontinued the study because of erosion followed by removal and four patients were lost to follow up.

Mean preoperative (baseline) IOP was 21 (SD 4) $\mathrm{mm} \mathrm{Hg}$; at 1,2 , and 3 years after surgery IOP was 15.3 (3.1) $\mathrm{mm} \mathrm{Hg}$ (35\% reduction), 16.6 (2.7) $\mathrm{mm} \mathrm{Hg} \mathrm{(29 \%} \mathrm{reduction),} \mathrm{and} 16$ (2.6) $\mathrm{mm} \mathrm{Hg}$ (22\% reduction), respectively (table 2 , fig 3 ). The overall success rate (IOP $\leqslant 21 \mathrm{~mm} \mathrm{Hg}$ with or without medications) was $94.4 \%$ at 2 years ( $17 / 18$ eyes) and $76.9 \%$ at last visit (20/26 eyes). The complete success rate (IOP $\leqslant 21 \mathrm{~mm} \mathrm{Hg}$ without medications) was $66.7 \%$ at 2 years (12/18 eyes) and $65.4 \%$ (17/26 eyes) at last visit (table 3 ).

The reduction of antiglaucoma medication use recorded following implantation of the Ex-PRESS device was

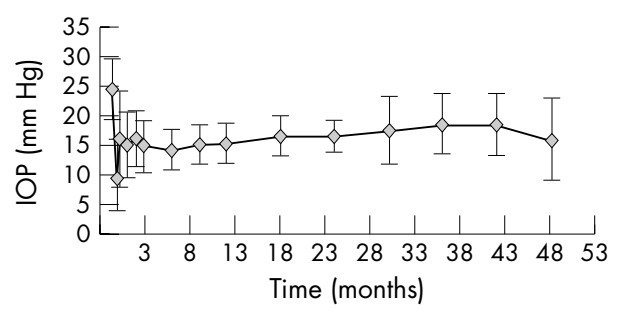

Figure 3 Efficacy, IOP dynamics ( $p=0.004$ for IOP reduction $>20 \%$ paired $t$ test).

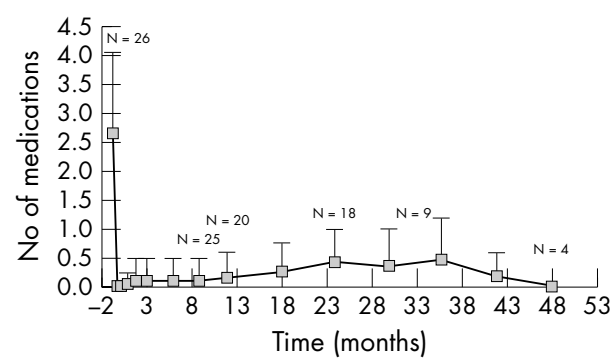

Figure 4 Number of medications over time $(p=0.0001$ for IOP reduction in medications, paired $t$ test). Six patients $(23 \%)$ were treated with medications at their last visit; five were treated with one medication; and one with two medications. significant. Six patients were treated pharmacologically at their last visit: five were treated with one medication and one with two medications (fig 4).

Visual acuity improved in 21 eyes; no change in VA was recorded in four eyes (fig 5). In one patient visual acuity decreased at the last visit (one Snellen line decrease).

Bleb needling in the postoperative period was performed in seven eyes: six of them associated with 5-FU injection. One

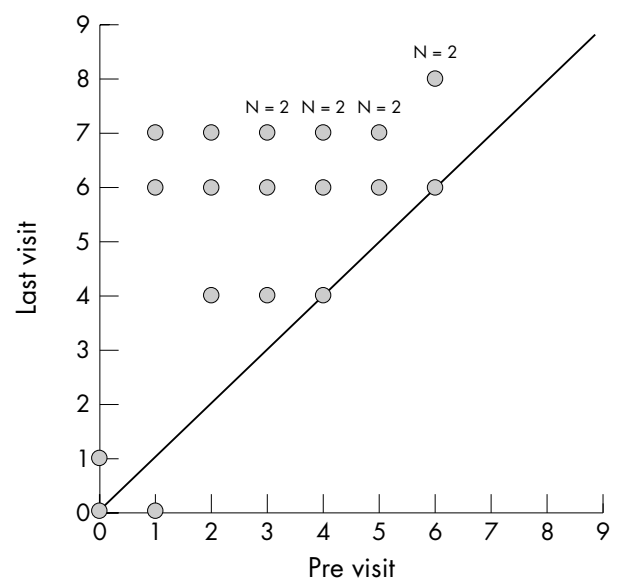

Figure 5 Visual acuity (VA) for patients with a minimum follow up of 2 months $(n=26)$. VA improvement in 21 eyes; no change in VA, four eyes; VA decrease, one eye (one Snellen line decrease).

Table 4 Postoperative interventions

\begin{tabular}{lll}
\hline & \multicolumn{2}{l}{ Eyes } \\
\cline { 2 - 3 } Intervention & No & $\%$ \\
\hline 5-FU injection & 1 & 3.8 \\
Needling with 5-FU & 6 & 23.1 \\
Needling without 5-FU & 1 & 3.8 \\
Total & 8 & 30.7 \\
\hline & & \\
\hline
\end{tabular}




\begin{tabular}{|c|c|c|}
\hline Complication & No (\%) & Comments \\
\hline Hyphaema $<2 \mathrm{~mm}$ & $3(11.5)$ & 1 day postop; all resolved spontaneously within 1 week \\
\hline Device rotation & $2(7.7)$ & $\begin{array}{l}1 \text { month postop treated by repositioning; } 2 \text { years postop } \\
\text { followed by erosion and is under observation (see below) }\end{array}$ \\
\hline Choroidal detachment & $1(3.8)$ & $\begin{array}{l}21 \text { months postop, due to vigorous rubbing of the eye; } \\
\text { spontaneously resolved }\end{array}$ \\
\hline Device iris touch & $1(3.8)$ & 2 months postop; calm eye \\
\hline Device malposition & $2(7.7)$ & $\begin{array}{l}1.5 \text { years postop spontaneously resolved; } 2.5 \text { years postop } \\
\text { with erosion. }\end{array}$ \\
\hline Erosion & $3(11.5)$ & $\begin{array}{l}2 \text { years postop associated with rotation and is under } \\
\text { observation (see above); } 2.5 \text { and } 3 \text { years postop one } \\
\text { followed by device removal and one by device replacement }\end{array}$ \\
\hline Suture granuloma & $1(3.8)$ & 2 months postop; spontaneously resolved \\
\hline Visual acuity decrease & $1(3.8)$ & \\
\hline
\end{tabular}

further patient received an injection of 5-FU without bleb needling (table 4).

Short term complications included three cases of hyphaema $(<2 \mathrm{~mm})$, one in the first postoperative day, all spontaneously resolved within l week; two cases of device rotation, one noticed at the first at first postoperative month and immediately repositioned and one 2 years after surgery, which caused conjunctival erosion; three cases of erosion: one at the second year of follow up, still now under observation, two at the second and third year respectively, one followed by device removal and one by device replacement; one case of choroidal detachment, probably related to vigorous rubbing of the eye as reported by the patient, spontaneously resolved; one case of iris contact with the implant, at second postoperative month, without sequelae (table 5).

\section{DISCUSSION}

The implantation of the Ex-PRESS R50 miniature stainless steel glaucoma drainage device in 26 eyes of 25 patients combined with phacoemulsification cataract extraction produced a cumulative overall success rate of $76.9 \%$ using an IOP $\leqslant 21 \mathrm{~mm} \mathrm{Hg}$ as an end point. Our success rate compares favourably with data reported in the literature for other filtering procedures: $50-100 \%$ for trabeculectomy, ${ }^{18-20}$ up to $87.5 \%$ for non-penetrating surgery, ${ }^{21}{ }^{22}$ and $25-90 \%$ for other glaucoma drainage devices. ${ }^{23-25}$

Our results confirm those obtained in a small case series using a trabecular meshwork bypass shunt where IOP and glaucoma medications were reduced in patients who were followed for up to 9 months. ${ }^{26}$

In studies comparing viscocanalostomy with trabeculectomy, the latter procedure has been shown to be more effective in controlling IOP while viscocanalostomy had fewer postoperative complications. ${ }^{212227-30}$ A study comparing trabeculectomy (retrospectively) in one eye and deep sclerectomy with collagen implant (prospectively) in the other eye of 20 patients found comparable success rates with IOP $<21 \mathrm{~mm} \mathrm{Hg}$ obtained in $40 \%$ of the deep sclerectomy eye group and $45 \%$ of the trabeculectomy eye group ${ }^{31}$; comparable IOP reductions were also reported in a prospective study of 78 eyes. ${ }^{32}$ However, another study noted lower levels of IOP with trabeculectomy although there were fewer complications with deep sclerectomy. ${ }^{33}$ Preliminary results from a study comparing deep sclerectomy with Ex-PRESS implant surgery indicated that the two procedures were comparable at 6 months of follow up. ${ }^{34}$

In our study, implantation of the Ex-PRESS device produced a low rate of short term complications, such as a shallow or flat chamber and hyphaema, similar to other filtering surgeries; there were no long term complications. Only six patients in our study required antiglaucoma medications at their last visit; comparatively better than commonly reported after trabeculectomy. ${ }^{6} 2035$

Bleb failure due to fibroblast proliferation is one of the main causes of failed filtration. In order to minimise the risk of scarring, the use of antimetabolites preoperatively and postoperatively is common.

\section{CONCLUSIONS}

In summary, results from our study demonstrate that implantation of the Ex-PRESS device is safe and is not associated with significant complications, both in short and long term. The cases of conjunctival erosion can be prevented by optimal intraoperative positioning of the device, mainly avoiding too anterior implantation. The correct positioning of the implant is the most crucial consideration for preventing complications.

This stainless steel device is safe and effective for reducing IOP and antiglaucoma medications in combination with cataract extraction.

Our results indicate that this procedure can be considered as an alternative to conventional filtering surgery for the control of IOP in patients with open angle glaucoma. However, further studies that directly compare the ExPRESS implant with trabeculectomy and other procedures are still required to assess precisely the role and relative advantages and disadvantages of each technique.

\section{Authors' affiliations}

C E Traverso, F De Feo, F Badalà, DiNOG, Clinica Oculistica, University of Genova, Italy

A Messas-Kaplan, Ophthalmology Department, Assaf Harofe Medical Center, Tsrifin, Israel

P Denis, Hôpital Edouard Herriot, Lyon, France

S Levartovsky, Barzilay Medical Center, Ashkelon, Israel

E Sellem, Centre Ophtalmologique Kléber, Lyon, France

Z Zagorski, Ophthalmology Department, Lublin University Medical School, Lublin, Poland

A Bron, Ophthalmology Department, University Hospital CHU Dijon, France

M Belkin, Goldschleger Eye Research Institute, Tel Hashomer, Israel

Competing interests: Professor Carlo E Traverso is also a clinical investigator for other surgical drainage glaucoma devices.

Informed consent: Approved by local ethics committees.

Declared interests: Carlo E Traverso, Audrey Messas-Kaplan, Philippe Denis, Shmuel Levartovsky, Eric Sellem, Zbigniew Zagorski, and Alain Bron have received funding from Optonol Ltd as clinical investigators for carrying out this study. Michael Belkin has proprietary interest in Optonol Ltd.

This work was presented as a poster at the Association for Research in Vision and Ophthalmology Annual Meeting 25-29 April 2004, Ft Lauderdale, FL, USA 


\section{REFERENCES}

1 The Ocular Hypertension Treatment Study. A randomised trial determines that topical ocular hypotensive medication delays or prevents the onset of POAG. Arch Ophthalmol 2002;120:701-3.

2 The AGIS Investigators. The Advanced Glaucoma Intervention Study (AGIS) 8. Risk of cataract formation after trabeculectomy. Arch Ophthalmol 2001;119:1771-80.

3 Lichter PR, Musch DC, Gillespie BW, et al and the CIGTS Study Group. Interim clinical outcomes in the collaborative initial glaucoma treatment study comparing initial treatment randomized to medication or surgery. Ophthalmology 2001;108:1943-53.

4 Cairns JE. Trabeculectomy. Preliminary report of a new method. Am J Ophthalmol 1968;66:673-9.

5 Rothman RF, Liebmann JM, Ritch R. Low-dose 5-fluorouracil trabeculectomy as initial surgery in uncomplicated glaucoma: long-term follow up. Ophthalmology 2000;107:1184-90.

6 The Fluorouracil Filtering Surgery Study Group. Fluorouracil filtering surgery study one-year follow-up. Am J Ophthalmol 1989;108:625-35.

7 Mermoud A, Schnyder CC, Sickenberg M, et al. Comparison of deep sclerectomy with collagen implant and trabeculectomy in open-angle glaucoma. J Cataract Refract Surg 1999;25:323-31.

8 El-Sayyad F, Helal M, El-Kholify H, et al. Non penetrating deep sclerectomy versus trabeculectomy in bilateral primary open-angle glaucoma. Ophthalmology 2000;107:1671-4.

9 Watson PG, Jakeman C, Ozturk M, et al. The complications of trabeculectomy (a 20 year follow-up). Eye 1990;4:425-38.

10 Quaranta L, Hitchings RA, Quaranta CA. Ab-interno goniotrabeculectomy versus mitomycin $\mathrm{C}$ trabeculectomy for adult open-angle glaucoma. Ophthalmology 1999;106:1357-62.

11 Higginbotham EJ, Stevens RK, Musch DC, et al. Bleb-related endophthalmitis after trabeculectomy with mitomycin C. Ophthalmology 1996;103:650-6.

12 Wolner B, Liebmann JM, Sassani JW, et al. Late bleb-related endophthalmitis after trabeculectomy with adjunctive 5-fluorouracil. Ophthalmology 1991;98:1053-60.

13 Khaw PT, Wells AP, Lim KS. Surgery for glaucoma in the 21 st century. Br J Ophthalmol 2002;86:710-11.

14 Molteno ACB. New implant for drainage in glaucoma. Animal trial. Br J Ophthalmol 1969;53:161-8.

15 Krupin T, Podos SM, Becker B, et al. Valve implants in filtering surgery Am J Ophthalmol 1976;81:232-5.

16 Krupin T, Kaufman P, Mandell A, et al. Filtering valve implant surgery for eyes with neovascular glaucoma. Am J Ophthalmol 1980;89:338-43.

17 Van de Veen G, Jongebloed WL, Worst JG. The gonioseton, a surgical treatment for chronic glaucoma. Doc Ophthalmol 1990;75:365-75.

18 The European Glaucoma Society. Incisional surgery. In: Terminology and guidelines for glaucoma, 2nd ed. Savona, Italy: Dogma, The European Glaucoma Society 2003, Ch 3, pp 33-6.
19 Goldenfeld M, Krupin T, Ruderman JM, et al. 5-fluorouracil in initial trabeculectomy. A prospective, randomized, multicentre study. Ophthalmology 1994;101:1024-9.

20 Mastropasqua L, Carpineto $P$, Ciancaglini $M$, et al. Delayed post-operative use of 5-fluorouracil as an adjunct in medically uncontrolled open angle glaucoma. Eye 1998;12:701-6.

21 Jonescu-Cuypers C, Jacobi P, Krieglstein G. Primary viscocanalostomy in white patients with open-angle glaucoma: a randomized clinical trial. Ophthalmology $2001 ; 108: 254-8$

22 Welsh NH, Delange J, Wasserman P, et al. The "deroofing" of Schlemm's canal in patients with open-angle glaucoma through placement of a collagen drainage device. Ophthalmic Surg Lasers 1998;29:216-26.

23 Wilson MR, Mendis U, Smith SD, et al. Ahmed glaucoma valve implant vs trabeculectomy in the surgical treatment of glaucoma: a randomized clinical trial. Am J Ophthalmol 2000;130:267-73.

24 Lloyd MA, Sedlak T, Hever DK, et al. Clinical experience with the single-plate Molteno implant in complicated glaucomas. Update of a pilot study. Ophthalmology 1992;99:679-87.

25 Valimaki J, Tuulonen A, Airaksinen PJ. Outcome of Molteno implantation surgery in refractory glaucoma and the effect of total and partial tube ligation on the success rate. Acta Ophthalmol Scand 1998;76:213-19.

26 Spiegel D, Kobuch K. Trabecular meshwork bypass tube shunt: initial case series. Br J Ophthalmol 2002;86:1228-31.

27 Luke C, Dietlein TS, Jacobi PC, et al. A prospective randomised trial of viscocanalostomy versus trabeculectomy in open-angle glaucoma: a 1-year follow-up study. J Glaucoma 2002;11:294-9

28 O'Brart DP, Rowlands E, Islan N, et al. A randomised, prospective study comparing trabeculectomy augmented with antimetabolites with a viscocanalostomy technique for the management of open angle glaucoma uncontrolled by medical therapy. Br J Ophthalmol 2002;86:748-54.

29 Sunaric-Megevand G, Leuenberger PM. Results of viscocanalostomy for primary open-angle glaucoma. Am J Ophthalmol 2001;132:221-8.

30 Stegmann R, Pienaar A, Miller D. Viscocanalostomy for open-angle glaucoma in black African patients. J Cataract Refract Surg 1999;25:316-22.

31 Ambresin A, Shaarawy T, Mermoud A. Deep sclerectomy with collagen implant in one eye compared with trabeculectomy in the other eye of the same patient. J Glaucoma 2002;11:214-20.

32 El Sayyad F, Helal M, El-Kholify H, et al. Nonpenetrating deep sclerectomy versus trabeculectomy in bilateral primary open-angle glaucoma. Ophthalmology 2000;107:1671-4

33 Chiselita D. Non-penetrating deep sclerectomy versus trabeculectomy in primary open-angle glaucoma surgery. Eye 2001;15(Pt 2):197-201.

34 Zarnowski T, Kawa P, Rakowska E, et al. Comparison of deep sclerectomy and miniature Ex-PRESS drainage device in open angle glaucoma. Ophthalmic Res 2001;33(Suppl 1):183.

35 Hitchings R. Efficacy of glaucoma treatment: the role of trabeculectomy. In: Jonsson B, Krieglstein G, eds. Primary open-angle glaucoma. Oxford: ISIS Medical Media, 1999:153-61. 


\section{PostScript}

\section{LETTERS}

If you have a burning desire to respond to paper published in the BJO, why not make use of our "rapid response" option?

Log on to our website (www.bjophthalmol. com), find the paper that interests you, and send your response via email by clicking on the "eletters" option in the box at the top right hand corner

Providing it isn't libellous or obscene, it will be posted within seven days. You can retrieve it by clicking on "read eletters" on our homepage.

The editors will decide as before whether to also publish it in a future paper issue.

\section{Disappearance of eyelid xanthelasma following oral simvastatin (Zocor)}

The major risk factors for coronary heart disease include smoking, elevated blood pressure, and elevated serum cholesterol. Risk reduction starts with identification of those at risk and then alteration of factors such as discontinuation of smoking, lowering of blood pressure, and reduction of serum cholesterol. Patients who should have blood cholesterol testing include those with family history of premature coronary heart disease or hyperlipidaemia, personal history of coronary heart disease, or clinical evidence of elevated lipids with features of xanthelasma, corneal arcus under age 50 years, and cutaneous xanthomas at any age. ${ }^{1}$ Two of the latter clinical features are ophthalmic and detection relies on the ophthalmologist.

Xanthelasma appear as multiple yellow placoid lesions in the periocular skin and represent a concentration of lipocytes in the dermis. ${ }^{2}$ There are numerous methods to manage the cosmetic appearance of xanthelasma, which typically involves surgical excision or laser ablation. ${ }^{3}$ We report a novel approach to management using oral cholesterol lowering medication and patience.

\section{Case report}

In 1992, a 68 year old male smoker with a history of hypertension and elevated serum cholesterol was referred for evaluation of a newly diagnosed iris mass. On examination, the visual acuity was 20/20 in both eyes. The mass was diagnosed as a benign iris naevus and observation was advised. Coincidental bilateral medial canthal and upper and lower eyelid xanthelasma were detected (fig 1A) The largest xanthelasma measured $16 \mathrm{~mm}$ in diameter. Observation was advised with tentative plan for surgical excision in the future. The patient was advised to continue his antihypertensive medications and anticholesterol medication (oral simvastatin (Zocor) $20 \mathrm{mg}$ once daily). At the 6 month follow up the iris nevus was stable and the xanthelasma persisted. Yearly examinations were advised. The patient did not return for 10 years. Surprisingly, the xanthelasma had completely resolved, leaving no clinical trace of subcutaneous lipid (fig 1B). He continued on his medications and serum cholesterol was normal.

\section{Comment}

In the Lipids Research Clinics Program Prevalence Study, xanthelasma and corneal arcus were associated with increased levels of serum cholesterol and low density lipoprotein cholesterol (LDL-C), especially in young males. ${ }^{4}$ People with either lesion had increased odds of having type IIa dyslipoproteinaemia. Adjusted odds ratios for ischaemic heart disease in participants with xanthelasma and corneal arcus were generally increased. The study concluded that the clinical findings of xanthelasma or corneal arcus, especially in young people, helped to identify those with plasma lipoprotein abnormalities. ${ }^{4}$

Management of patients with elevated LDL-C include both low cholesterol diet and cholesterol lowering medications, the most popular of which are the statins. There are currently five statin drugs on the market in the United States and these include lovastatin (Mevacor, Altocor), simvastatin (Zocor), pravastatin (Pravachol), fluvastatin (Lescol), and atorvastatin (Lipitor). The major effect of these medications is to lower LDL-C by slowing down the production of cholesterol and by increasing the liver's ability to metabolise the LDL-C in the blood. Statins reduce LDL-C by approximately $40 \%$ and produce a modest increase in high density lipoprotein-cholesterol (HDL-C). These medications are given daily in the evening to take
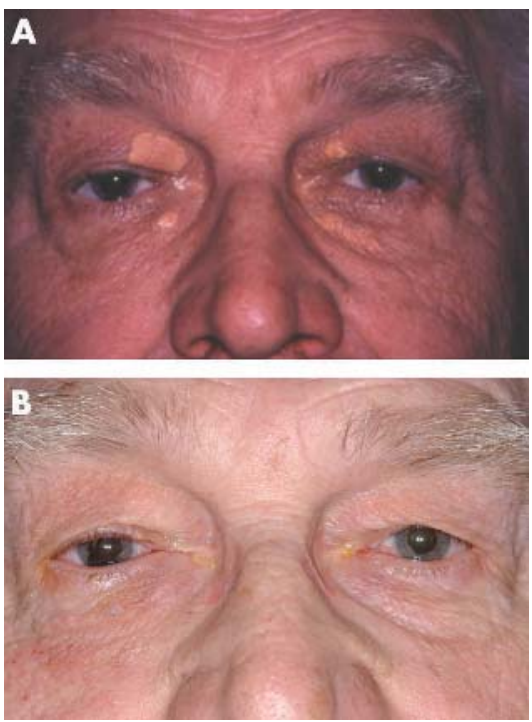

Figure 1 A 68 year old man with hypertension and elevated cholesterol and bilateral upper and lower eyelid xanthelasma. He was on oral simvastatin for hypercholesterolaemia. (A) January 1992. At presentation, the multifocal yellow xanthelasma are noted. (B) April 2002. After 10 years lost to ophthalmic follow up, the patient returned with complete resolution of xanthelasma. advantage of the fact that the body makes more cholesterol at night. Statins reduce measured blood LDL-C within 4-6 weeks. In a study of 20536 patients, this resulted in long term reduction in coronary heart disease, stroke, and mortality. ${ }^{5}$

Simvastatin is derived synthetically from a fermentation product of Aspergillus tereus. Simvastatin is hydrolysed to an inhibitor of an enzyme responsible for cholesterol synthesis. In the Multicenter Anti-Atheroma Study, simvastatin slowed the progression of atherosclerosis, measured by vascular stenosis diameter on angiography, and decreased significantly the development of new lesions. ${ }^{5}$

To our knowledge, there have been no previous reports on the effect of statins on eyelid xanthelasma. A PubMed search for keywords "statin and xanthelasma" and simvastatin and xanthelasma" yielded no relevant publications. The management of eyelid xanthelasma includes surgical excision, microsurgical inverted peeling, laser inverted resurfacing, photovaporisation using carbon dioxide laser, and application of bichloracetic acid. Patients with the highest recurrence rate are those with elevated cholesterol. These local treatments do not address possible systemic associations. By observations in this report, we suggest that serum cholesterol be evaluated and if elevated, oral statin combined with dietary cholesterol restriction might result in resolution of xanthelasma over time, but, more importantly, reduction of patient cardiac risk.

C L Shields, A Mashayekhi, J A Shields Ocular Oncology Service, Wills Eye Hospital, Thomas Jefferson University, Philadelphia, PA, USA

P Racciato Pocono Medical Center, Stroudsburg, PA, USA

Correspondence to: Carol L Shields, MD, Ocular Oncology Service, Wills Eye Hospital, 840 Walnut Street, Philadelphia, PA 19107, USA; carol.shields@shieldsoncology.com

doi: 10.1136/bjo.2004.053058

Accepted for publication 13 September 2004

Support provided by the Eye Tumor Research Foundation, Philadelphia, PA (CLS), the Macula Foundation, New York, NY (CLS), the Rosenthal Award of the Macula Society (CLS), and the Paul Kayser International Award of Merit in Retina Research, Houston TX (JAS)

\section{References}

1 Farmer JA, Gotto AM Jr. The Heart Protection Study: expanding the boundaries for high-risk coronary disease prevention. Am J Cardiol 2003;3:3i-9i.

2 Shields JA, Shields CL. Atlas of eyelid and conjunctival tumors. Philadelphia: Lippincott Williams \& Wilkins, 138-9.

3 Rohrich RJ, Janis JE, Pownell PH. Xanthelasma palpebrarum: a review and current management principles. Plast Reconstr Surg 2002;110:1310-14.

4 Segal P, Insull W Jr, Chambless LE, et al. The association of dyslipoproteinemia with cornea arcus and xanthelasma. The Lipid Research Clinics Program Prevalence Study. Circulation 1986;73:108-18. 
5 Dumont JM. Effect of cholesterol reduction by simvastatin on progression of coronary atherosclerosis: design, baseline characteristics, and progress of the Multicenter Anti-Atheroma Study (MAAS). Control Clin Trials 1993; 14:209-28.

New onset diplopia: 14 years after retinal detachment surgery with a hydrogel scleral buckle

In 1979, the hydrogel explant (Miragel, Waltham, MA, USA) was introduced as a scleral buckling material in the surgical management of retinal detachment. ${ }^{1}$ It was widely used in the 1980s and early 1990s as it was initially believed to be well tolerated, less prone to infection, and easy to manipulate. ${ }^{2}$ However, long term complications related to swelling and fragmentation of the explant have been reported over recent years, ${ }^{3-6}$ resulting in discontinuation of its use in 1995.

\section{Case report}

A 36 year old healthy man presented on 2003 with symptoms of mild right ocular discomfort. Past ocular history included a right retinal detachment repair 14 years previously, using a $907(3 \times 5 \mathrm{~mm})$ Miragel scleral buckle (Miragel, Medical Instruments Research Associates, Waltham, MA, USA), sutured to the inferior sclera. On examination, visual acuity was 20/120 right and 20/20 left. There was no diplopia or limitation of eye movements. What was thought to be a small conjunctival cyst was noted inferiorly but, otherwise, the ocular examination was unremarkable and the retina was secure.

A year later (2004), he presented with increasing marked right ocular discomfort and diplopia in all fields. His visual acuity was unchanged, but there was marked restriction of elevation and reduction in adduction of the right eye and binocular diplopia in all fields of gaze. A tense swelling of the inferior conjunctiva was noted (fig 1, top), intraocular pressure was normal, and the retina was flat with a moderate anterior buckle effect. Computed tomography (CT) (fig 1, bottom) demonstrated a right orbital circumferential soft tissue mass surrounding the lower half of the globe with a small area of calcification. The initial diagnosis was a postoperative giant conjunctival cyst and the patient underwent surgery.

Intraoperatively, exploration revealed no conjunctival cyst, but a large encapsulated scleral buckle. The explant was friable, gellike, and translucent, but could be removed in one piece (fig 2). A $3 \mathrm{~mm}$ diameter area of scleral thinning associated with calcification was found underlying the buckle inferotemporally. At 1 month follow up the patient was asymptomatic with no diplopia, unrestricted extraocular movements, and the retina was flat.

\section{Comment}

Hydrogel explants are composed of a low molecular weight hydrophilic material that is water permeable. These explants have a tendency to absorb water over the years and increase dramatically in size. The resulting complications range from a non-tender subconjunctival mass to intraocular or external extrusion. ${ }^{3-6}$ The long time lapse from buckle surgery may result in a high misdiagnosis rate. Kearney et $a l^{6}$ reported 17 eyes of

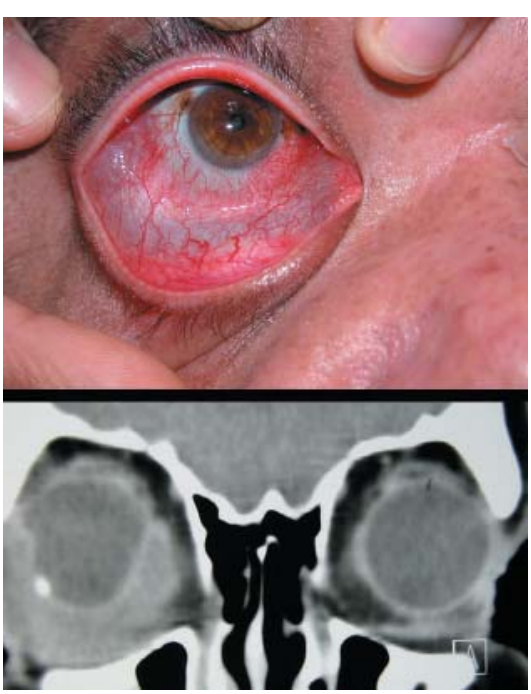

Figure 1 Top: Clinical photograph of the right eye showing bulging of the inferior fornix. Bottom: Coronal computed tomographic scan showing a circumferential soft tissue mass surrounding lower half of the globe and a small area of calcification on the inferotemporal sclera.

patients with complications related to hydrogel explant swelling. In nine cases the initial diagnosis was incorrect, being mainly Graves' disease, idiopathic orbital fibrosis, and a subconjunctival inclusion cyst.

In our case, there was a profound increase in the explant volume during a 14 year period. The resulting diplopia and restriction of extraocular movement as well as the clinical evaluation mimicked a giant orbital inclusion cyst. The correct diagnosis was only made intraoperatively. Scleral thinning and necrosis as seen in our case has been reported previously, ${ }^{7}$ resulting in intraoperative vitr-
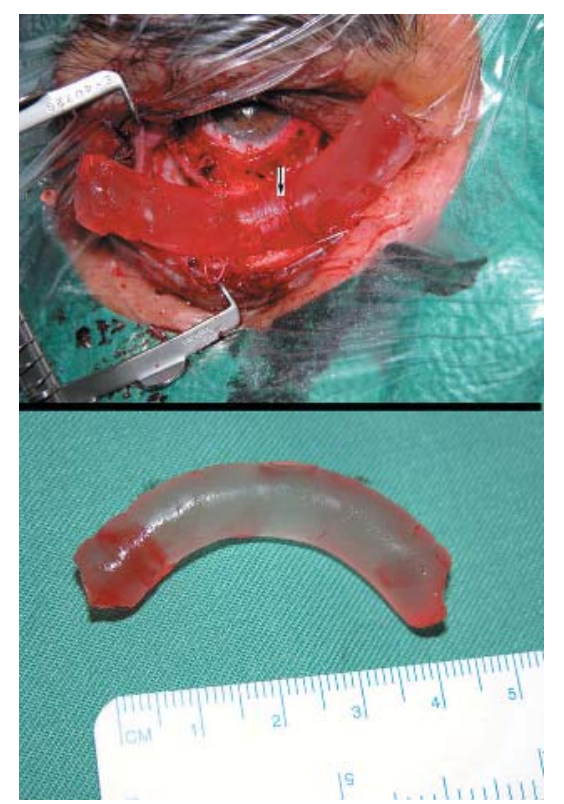

Figure 2 Top: Intraoperative photograph showing the swollen hydrogel buckle under the inferior rectus muscle (arrow). Bottom: The hydrogel buckle after removal. eous leak after removal of the expanded explant. ${ }^{8}$ In our patient, there was an area of thinned sclera, but the surrounding calcification and the early removal of the explant prevented vitreous leak.

It is important to note that patients who have undergone scleral buckling with hydrogel explants before 1995 are at risk of developing this complication. Symptoms of progressive diplopia, pain, and restriction of extraocular muscle movement in these patients should also raise the possibility of explant expansion. The assistance of a retinal surgeon may sometimes be required because of the increased risk of scleral thinning and leakage of liquid vitreous intraoperatively.

I Leibovitch, J Crompton, D Selva Oculoplastic and Orbital Unit, Department of Ophthalmology, Royal Adelaide Hospital, University of Adelaide, South Australia, Australia

Correspondence to: Dinesh Selva Oculoplastic and Orbital Unit, Department of Ophthalmology, Royal Adelaide Hospital, North Terrace, Adelaide, 5000, South Australia, Australia; Awestwoo@mail.rah.sa.gov.au

doi: 10.1136/bjo.2004.053868

Accepted for publication 27 August 2004

\section{References}

1 Refojo MF, Natchiar G, Lui HS, et al. New hydrophilic implant for scleral buckling. Ann Ophthalmol 1980;12:88-92.

2 Tolentino FI, Roldan M, Nassif J, et al. Hydrogel implant for scleral buckling. Long-term observations. Retina 1985;5:38-41.

3 Marin JF, Tolentino Fl, Refojo MF, et al. Long term complications of the MAI hydrogel intrascleral buckling implant. Arch Ophthalmol 1992;110:86-8.

4 Roldan-Pollares M, Castillo Sanz JL, Alwad ElSusi $S$, et al. Long term complications of silicone and hydrogel explants in retinal reattachment surgery. Arch Ophthalmol 1999;117:197-201.

5 Oshitari K, Hida T, Okada AA, et al. Long-term complications of hydrogel buckles. Retina 2003;23:257-61.

6 Kearney JJ, Lahey JM, Borirakchanyavat S, et al. Complications of hydrogel explants used in scleral buckling surgery. Am J Ophthalmol 2004;137:96-100.

7 Le Rouic JF, Bettembourg O, D'hermies F, et al. Late swelling and removal of miragel buckles: a comparison with silicone indentations. Retina 2003:23:641-6

8 Metz HS, Rose S, Burkat C. Late-onset progressive strabismus associated with a hydrogel scleral buckle. J AAPOS 2004;8:72-3.

\section{Inverse globe retraction syndrome complicating recurrent pterygium}

Often larger and more aggressive than the original lesion, recurrent pterygia can cause visual symptoms that are most often secondary to their mechanical effects on the cornea. ${ }^{1}$ We report a case of inverse globe retraction syndrome (that is, retraction during abduction) due to the restrictive effect of a recurrent pterygium and the management of this complication.

\section{Case report}

A 28 year old man without a medical history or ocular symptoms underwent pterygium excision in his left eye with a superotemporal conjunctival autograft and intraoperative mitomyocin C. Three weeks postoperatively, he noted a feeling of pressure in the left eye 

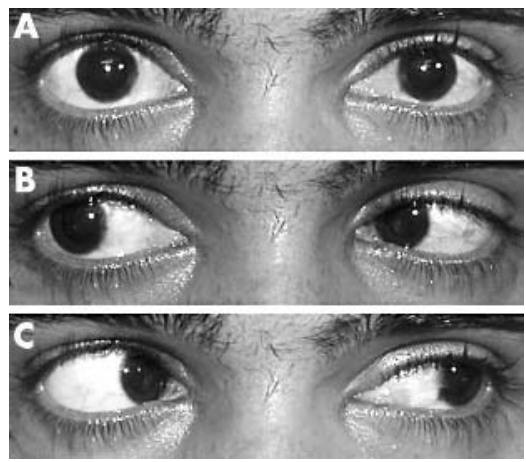

Figure 1 The patient's appearance at presentation in (A) primary gaze, (B) right gaze, (C) left gaze. There is relative enophthalmos in the left eye that increases during left gaze. During right gaze, adduction in the left eye occurs with less effort than abduction in the right eye.

and diplopia during left gaze. Two months postoperatively he presented to us and his ophthalmic examination was significant for the following-left eye: $2 \mathrm{~mm}$ enophthalmos relative to right eye, recurrence of the pterygium, globe retraction during left gaze secondary to a leash effect from the recurrent pterygium, and minimal abduction deficiency (fig 1). One month later, his examination was stable and surgery was scheduled. Intraoperatively forced ductions showed -1 (on a scale of 1 to 4 ) limitation of abduction in the left eye. The left eye was positioned in abduction and a $6 \mathrm{~mm}$ vertical incision was made in the nasal conjunctival $3 \mathrm{~mm}$ posterior to the limbus. A $5 \times 6 \mathrm{~mm}$ graft of amniotic membrane (locally procured and kept frozen before use) was sutured in the resultant gap in the conjunctiva using 9-0 Vicryl suture after the conjunctival edges were undermined. Two months following this procedure, the patient's feeling of pressure was relieved and there is neither diplopia nor globe retraction during left gaze (fig 2).

\section{Comment}

Inverse globe retraction syndrome is rare..$^{2-5} \mathrm{It}$ has been reported as being caused by medial
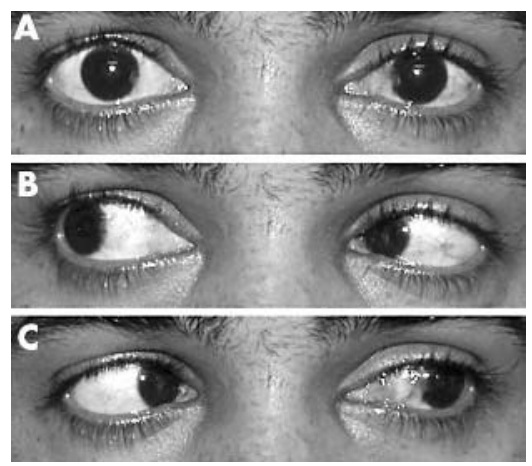

Figure 2 The patient's appearance 6 weeks after amniotic membrane placement in (A) primary gaze, (B) right gaze, (C) left gaze. There is no longer globe retraction left eye during left gaze. During right gaze, adduction in the left eye occurs with effort similar to that needed for abduction in the right eye. rectus abnormality, ${ }^{2}$ innervational misdirection, ${ }^{3}$ and secondary to restriction from traumatic tissue capture in the medial orbital wall. $^{45}$ The current case demonstrates another cause for the syndrome, globe restriction as a result of a leash effect from aggressive pterygium recurrence. The risk of pterygium recurrence after initial pterygium removal is minimised by the technique of conjunctival autograft with adjunctive mitomyocin $\mathrm{C}^{6}$; however, because aggressive recurrence is still possible initial pterygium surgery should only be performed for patients with significant cosmetic and/or functional concerns. For the management of inverse globe retraction syndrome complicating recurrent pterygium in this case, the use of amniotic membrane as a tissue spacer permitted excellent functional improvement.

Correspondence to: A O Khan, King Khaled Eye Specialist Hospital, PO Box 7191 Riyadh, Saudi Arabia; arif.khan@mssm.edu

doi: 10.1136/bjo.2004.053850

Accepted for publication 2 September 2004

\section{References}

1 Hirst LW. The treatment of pterygium. Surv Ophthalmol 2003;48:145-80

2 Lew H, Lee JB, Kim HS, et al. A case of congenital inverse Duane's retraction syndrome. Yonsei Med J 2000;41:155-8.

3 Chatteriee PK, Bhunia J, Bhattacharyya I. Bilateral inverse Duane's retraction syndrome-a case report. Indian J Ophthalmol 1991;39:183-5.

4 Davidson TM, Olesen RM, Nahum AM. Medial orbital wall fracture with rectus entrapment. Arch Otolaryngol 1975;101:33-5.

5 Gittinger JW Jr, Hughes JP, Suran EL. Medial orbital wall blow-out fracture producing an acquired retraction syndrome. J Clin Neuroophthalmol 1986;6:153-6.

6 Sanchez-Thorin JC, Rocha G, Yelin JB. Metaanalysis on the recurrence rates after bare sclera resection with and without mitomycin $C$ use and conjunctival autograft placement in surgery for primary pterygium. Br J Ophthalmol 1998;82:661-5.

\section{Seeing is not believing}

We describe a case of posterior cortical atrophy presenting with progressive visuoperceptual and visuospatial difficulties, but with no abnormalities on standard ophthalmological examination.

\section{Case report}

The patient, a 53 year old right handed woman, with well controlled primary generalised epilepsy, presented to her optometrist with a l year history of deterioration in vision. She had particular difficulties with walking downstairs and following text while reading. She could read 6/12+2 RE (with $-0.75 /-0.25 \times 90$ correction) and $6 / 12+3$ (with -0.75 correction) LE. With +2.25 correction she could read N5 slowly with each eye. On subsequent ophthalmological review no significant abnormality was found on examination and no specific diagnosis was made.

Over the following months her vision deteriorated. She reported difficulties following a line while writing and was unable to tell when a glass was full when pouring a drink. Her husband thought that she was unable to see things in her peripheral vision. This culminated in her crashing her car. She did not have any memory difficulties, she had preserved insight, and there had been no change in personality.

On admission to our unit her visual acuity was 6/18 RE and 6/12 LE with the above correction. She was able to read slowly at N5 corrected with each eye but was unable to name any of the Ishihara plate numbers including the test plate, despite being able to name the colours, trace the outline of the numbers with her finger, and read numbers in normal print. Confrontation visual fields were essentially full although she was slow to recognise objects in her peripheral visual fields owing to an apparent narrowing of attention to foveal vision and had optic ataxia, in that she was unable to localise in space, by pointing, objects placed in her peripheral visual fields. On Goldmann perimetry her visual fields appeared somewhat constricted, probably related to her difficulties with attention, but, importantly, no hemianopia was demonstrated (fig 1). Pupillary responses were normal as was fundal examination. On eye movement testing she had broken smooth pursuit eye movements, although she was able to generate voluntary saccades. The rest of the neurological examination was unremarkable.

Her mini-mental state examination score was $28 / 30$. She had some deficits in verbal abstract reasoning and made occasional phonemic errors in speech. She had mild dyscalculia and dyspraxia, but she was able to differentiate left from right and name body parts. She had mild memory impairment, although these were mainly in tasks requiring visual input. She demonstrated simultanagnosia in that she was unable to see the whole of a picture and only described parts of it.

On testing with the cortical vision screening tes $\mathrm{t}^{1}$ she passed the hue discrimination test, the word reading test, face perception test, the crowding test of letter reading and was able to detect the presence of a circle in the shape detection test but was unsure what to say if it was not present. On the symbol
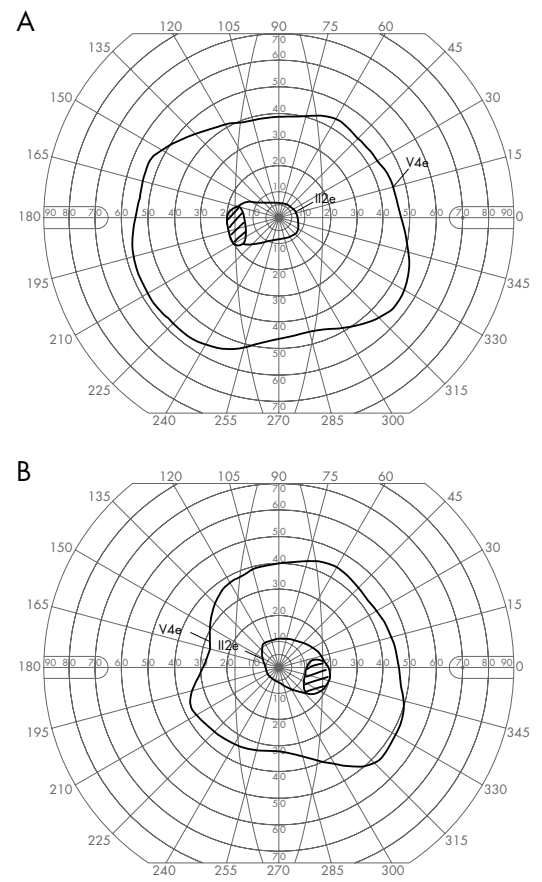

Figure 1 Goldmann perimetry (V4e and II2e). 


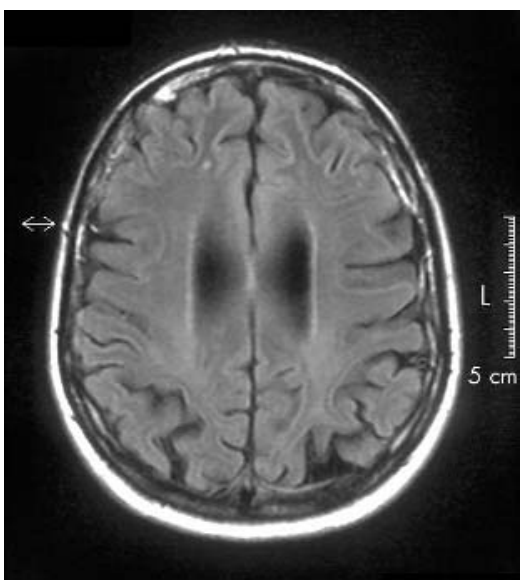

Figure 2 FLAIR MRI demonstrating mainly posterior cortical atrophy.

acuity test her Snellen equivalent was 6/18 with each eye, despite being able to read text at N5, which suggested that she had more difficulty in identifying shapes than words. She failed tests of shape discrimination and size discrimination to indicate bilateral occipital dysfunction and also failed tests of scattered dot counting and fragmented numbers to indicate right parietal dysfunction.

Blood tests and cerebrospinal fluid examination were both normal. Magnetic resonance imaging demonstrated cerebral atrophy most marked in the both posterior parietal and occipital lobes (fig 2). A diagnosis of posterior cortical atrophy was made.

\section{Comment}

This woman therefore presented with progressive visuoperceptual and visuospatial difficulties, but had no abnormalities on ophthalmological examination. She had some features of Balint's syndrome (that is, simultanagnosia and optic ataxia) $)^{2}$ and other cognitive deficits. Her poor distance visual acuity may have been related to her poor visuospatial ability, given her good, albeit slow, near vision. Her inability to recognise any of the Ishihara plates, with otherwise normal colour vision, is probably a reflection of her other visuoperceptual difficulties, which has been reported before in similar patients, ${ }^{3}$ although difficulty with figureground discrimination cannot be excluded.

Posterior cortical atrophy is a clinical and radiological diagnosis based upon the presence of occipitoparietal abnormalities with initially preserved occipitotemporal (face and colour recognition) and anterior cerebral function. ${ }^{45}$ It is thought to be as a result of Alzheimer's disease, in most cases, ${ }^{50}$ although the syndrome has been described with other pathologies-for example, subcortical gliosis, Creutzfeld-Jakob disease, and progressive multifocal leucoencephalopathy. ${ }^{57}$ Although it is rare, it should be suspected in any patient presenting with visuoperceptual or visuospatial difficulties in the absence of any signs on standard ophthalmological examination. Screening tests for higher visual function deficits can then be employed. ${ }^{168}$

The corollary of this is that a patient with an established diagnosis of dementia should be tested for disorders of higher visual function, because a patient with otherwise mild cognitive deficits may still be driving. ${ }^{6}$

\section{S J Hickman, D Alvares, H Crewes, R J Wise,}

A N Gale

Royal Free Hospital, Pond Street, London NW3 2QG,

Correspondence to: Simon J Hickman, Royal Free Hospital, Pond Street, London NW3 2QG, UK; simonhickman@btinternet.com

doi: 10.1136/bjo.2004.054429

Accepted for publication 28 September 2004

\section{References}

1 James-Galton M, Plant GT, Warrington EK. The cortical vision screening test (CORVIST). London: Thames Valley Test Company, 2001.

2 Balint R. Seelenlähmung des "Schauens", optische Ataxie, Raümliche Störung der Aufmerksamkeit. Monatsschriff fur Psychiatrie und Neurologie 1909;25:51-80.

3 Mendez MF, Cherrier MM. The evolution of alexia and simultanagnosia in posterior cortical atrophy. Neuropsychiatry Neuropsychol Behav Neurol 1998;11:76-82.

4 Benson DF, Davis RJ, Snyder BD. Posterior cortical atrophy. Arch Neurol 1988;45:789-93.

5 Victoroff J, Ross GW, Benson DF, et al. Posterior cortical atrophy. Neuropathologic correlations. Arch Neurol 1994;51:269-74.

6 Fletcher WA. Ophthalmological aspects of Alzheimer's disease. Curr Opin Ophthalmol 1994;5:38-44.
7 Ayuso-Peralta L, Jiménez-Jiménez FJ, Tejeiro J, et al. Progressive multifocal leukoencephalopathy in HIV infection presenting as Balint's syndrome. Neurology 1994;44:1339-40.

8 Tranel D. Assessment of higher-order visua function. Curr Opin Ophthalmol 1994;5:29-37.

\section{Radial optic neurotomy in combined cilioretinal artery and central retinal vein occlusion}

Combined cilioretinal artery and central retinal vein occlusion (CRVO) is a rare clinical finding, first described by Oosterhuis. ${ }^{1}$ The pathogenesis of this condition is not well established and remains controversial. Most reports postulate that the initial CRVO causes an elevation of the intraluminal capillary pressure and induces a consecutively reduced perfusion pressure at the arterial side. Since the perfusion pressure of the cilioretinal artery is lower than the central artery, it becomes relatively occluded. $^{2-4}$ Recently Opremcak et al described radial optic neurotomy (RON) involving pars plana vitrectomy (PPV) and radial incision of the optic nerve to treat CRVO. ${ }^{5}$ We report this new surgical approach in a patient with combined cilioretinal artery occlusion and CRVO.

\section{Case report}

A healthy 64 year old woman complained of unilaterally blurred vision for the past 3 days Her visual acuity (VA) was 20/200 in the right eye (RE) and 20/20 in the left eye (LE) The anterior segment in both eyes was unremarkable on slit lamp examination. Fundus examination RE demonstrated a whitening of the macula corresponding to an area supplied by an cilioretinal artery. The retinal veins were dilated, accompanied by adjacent retinal haemorrhages (fig 1A). The fundus of the left eye appeared normal. Fluorescein angiography (FA) RE revealed a delayed arteriovenous (AV) perfusion time of 13 seconds. Systemic evaluation of the patient did not reveal any general disease. Although treated systemically with corticosteroids $^{6}$ and low dose heparin for 4 weeks, she developed CRVO with severe disc oedema, extensive dilatation of the retina veins, radial orientated intraretinal haemorrhages, and cotton wool spots (fig 1B). On FA there was a reduced perfusion time of the cilioretinal artery in addition to the typical
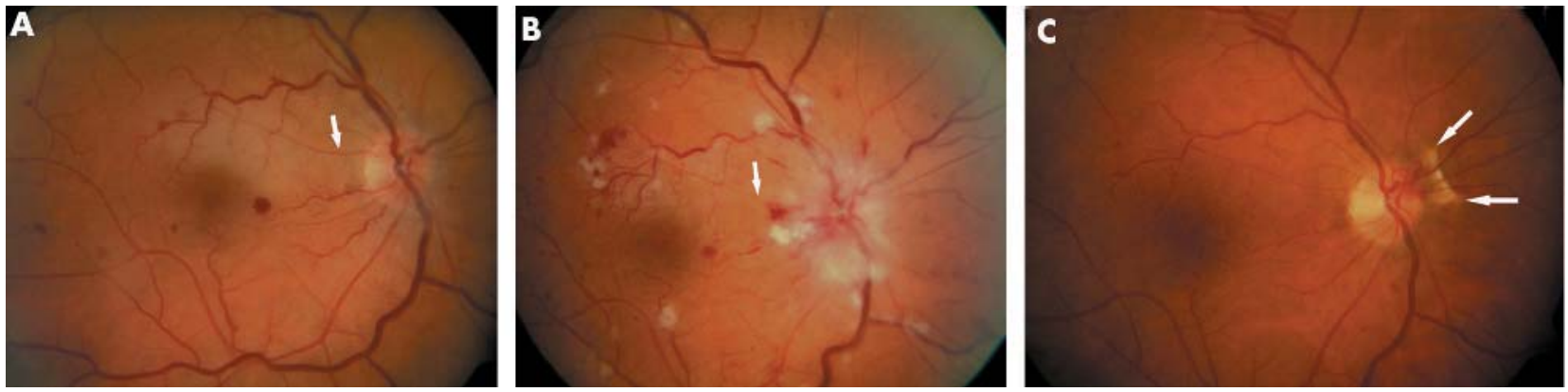

Figure 1 Colour fundus photography of the right eye. (A) 3 days after decrease of VA. A whitening of the macula corresponding to an area supplied by the cilioretinal artery (white arrow) can be seen. The retinal veins appear dilated and sparse retinal haemorrhages are visible. (B) 1 day preoperatively. The cilioretinal artery appears with reduced diameter (white arrow), typical picture of CRVO with disc oedema without visible disc margin, extensive dilatation of the retinal veins, radial orientated intraretinal haemorrhages, and several cotton wool spots are present. (C) 10 weeks postoperatively. The optic disc appear with sharp margin, the diameter of the retinal veins are similar to those of the left eye. Chorioretinal whitening at the 2 and 4 o'clock position at the disc margin indicate the location, direction, and length of the radial cuts by RON (white arrows). Remaining signs of the CRVO, including retinal haemorrhages or macular oedema have vanished. The cilioretinal artery appears with physiological diameter. 
signs of CRVO (fig 2A). Based on positive results of RON in CRVO, we offered this treatment to our patient. After she signed an informed consent, RON was performed with two radial cuts at the nasal edge of the optic disc. After 2 days disc oedema was significantly reduced with sharp visible disc margins. Two months postoperatively the retinal haemorrhages, cotton wool spots, and disc oedema resolved and her VA improved to 20/ $25 \mathrm{RE}$ (fig IC). FA demonstrated a physiological AV perfusion time of less than 3 seconds and no signs of an occluded cilioretinal artery (fig 2B).

\section{Comment}

Combined cilioretinal artery occlusion and CRVO are discussed as a separate clinical entity in the literature, ${ }^{1-4}$ and its treatment by RON has not been described. Opremcak et al postulated that a surgical decompression of the optic disc and scleral ring by RON may contribute to an improved venous perfusion in CRVO. Our patient demonstrated additional signs of an arterial occlusion with delayed filling of the cilioretinal artery in the macula, which may induce permanent functional loss. The underlying pathomechanism of CRVO remain unknown, current discussion leans towards an intraluminal occlusion by a thrombus, increased extravasal pressure, or a combination of both as possible causes. In addition the therapeutic effect of RON is also questionable. It remains unclear as to whether RON causes a decompression of the optic disc increasing the ocular blood flow or

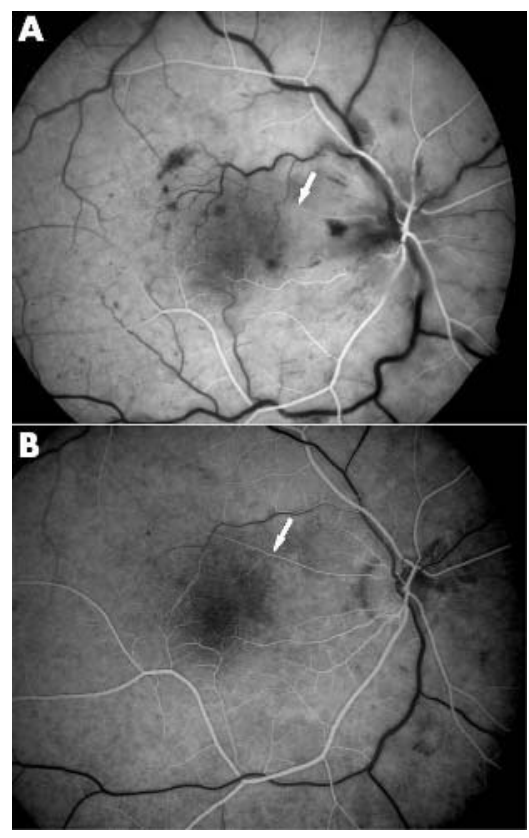

Figure 2 Fluorescein angiography of the right eye. (A) Preoperative, arterial phase (14 seconds after dye injection). A delayed filling of the cilioretinal artery becomes apparent (white arrow). The macular area supplied by the cilioretinal artery appear hypofluorescent as a result of retinal thickening (B) 10 weeks postoperatively, arterial phase (14 seconds after dye injection). The filling of the cilioretinal artery occurs at 13 seconds and appears similar to the central retinal artery. There are no signs of non-perfused areas or ischaemia. induces the formation of new chorioretinal shunt vessel. ${ }^{8}$ In our case the goal of RON was to reduce the capillary pressure, therefore increasing the perfusion in the cilioretinal artery and thus improving central vision. Patients with combined occlusive AV disease may benefit from RON by improving their haemodynamic perfusion pressure, retinal anatomy, and consecutive central visual function.

S Mennel, K Droutsas, C H Meyer, J C Schmidt, P Kroll

Department of Ophthalmology, Philipps-University Marburg, Germany

Correspondence to: Stefan Mennel, MD, Department of Ophthalmology, Philipps-University Marburg, Robert-Koch-Strasse 4, 35037 Marburg, Germany; stefan.mennel@lycos.com

doi: 10.1136/bjo.2004.054858

Accepted for publication 20 October 2004

Financial support: none.

Proprietary interest: none.

\section{References}

1 Oosterhuis JA. Fluorescein fundus photography in retinal vein occlusion. In: Henkes $\mathrm{HE}$, eds. Perspectives in ophthalmology. Amsterdam Excerpta Medica, 1968:29-47.

2 Schatz H, Fong AC, McDonald HR, et al. Cilioretinal artery occlusion in young adults with central retinal vein occlusion. Ophthalmology 1991;98:594-601.

3 Keyser BJ, Duker JS, Brown GC, et al. Combined central retinal vein occlusion and cilioretinal artery occlusion associated with prolonged retinal arterial filling. Am J Ophthalmo

1994;117:308-13.

4 Murray DC, Christopoulou D, Hero M. Combined central retinal vein occlusion and cilioretinal artery occlusion in a patient on hormone replacement therapy. Br J Ophthalmol 2000:84:549-50

5 Opremcak EM, Bruce RA, Lomeo MD, et al. Radial optic neurotomy for central retinal vein occlusion: a retrospective pilot study of 11 consecutive cases. Retina 2001;21:408-15.

6 Hausmann N, Richard G. Effect of high dose steroid bolus on occlusion of ocular central artery: angiographic study. BMJ 1991;303:1445-6.

7 Hayreh SS. Management of central retinal vein occlusion. Ophthalmologica 2003;217:167-88.

8 Garcia-Arumi J, Boixadera A, MartinezCastillo V, et al. Chorioretinal anastomosis after radial optic neurotomy for central retinal vein occlusion. Arch Ophthalmol 2003;121:1385-91.

\section{MAILBOX}

\section{Value based medicine}

In a fine recent editorial, Drs Melissa and Gary Brown raised issues at the nexus of health policy and clinical science. ${ }^{1}$ As utility assessment is relatively new to the visual sciences, understanding both the assumptions behind this work and the consequences of relaxing those assumptions is essential for the conduct of high quality research and appropriate interpretation of the results.

The use of community elicited utilities (that is, including people without the disease in the elicitation study) in economic evaluation should be given more than minimal consideration. Economic evaluations are intended to inform health policy makers by assessing the value society places on the cure or prevention of disease. Community based utilities typically reflect larger estimates of utility loss than those elicited from patients and result in a more favourable analysis of the cost effectiveness of preventive interventions than those relying on patient elicited utilities. ${ }^{2}$ At the same time, estimating community elicited utilities requires the development of easily understood scenarios to assist community members in understanding life with the disease, ${ }^{3}$ after leading investigators prefer to rely on patient elicited utilities. Rather than dismiss the community elicited approach, economic evaluation in ophthalmology would be greatly facilitated by development of a catalogue of community elicited utilities related to old disease developed through the standard gamble or time tradeoff methods or responses to health status questionnaires that include algorithms to estimate health utilities.

While the Browns caution against the use of functionally based health related quality of life instruments (for example, the NEI-VFQ) in economic evaluation, we would like to offer an alternative explanation for this concern. Most disease specific instruments are based in psychometric theory and designed to measure change in the patient's self reported health status in investigator defined domains. ${ }^{4}$ Domain scores do not reflect the importance the respondent assigns to the activities, but scoring algorithms developed by the instrument designer. The result is a metric that is often meaningful to clinicians but does not reflect the value the patient or society places on the health state. This limits generalisability across disease groups, as well as investigators' ability to comment on the most efficient method to screen for, or treat, an ophthalmic condition affecting multiple areas of physical, mental, or emotional function.

Finally, the standard gamble elicitation method should not be dismissed off handedly. More frequent use of the time trade-off reflects the method's intuitive appeal rather than theoretical superiority. As opposed to the time trade-off in which the anchor event (typically, death, blindness, etc) occurs in the future, in the standard gamble the event is immediate. This provides an estimate of the person's risk preference unconfounded by time. The time trade-off consistently results in higher estimates of utility loss than the standard gamble, ${ }^{56}$ potentially resulting in an overestimation of the cost-effectiveness of treatment or prevention.

We hope that our comments will help future work to be pragmatic and theoretically sound. This is necessary if we are to properly characterise the appropriateness of our methods as well as the value of our findings.

S M Kymes

Washington University School of Medicine, Department of Ophthalmology and Visual Sciences, 660 South Euclid, Campus Box 8096, Saint Louis, MO 63116, USA

\section{K D Frick}

Johns Hopkins Bloomberg School of Public Health Department of Health Policy and Management, Baltimore, MD, USA

Correspondence to: Dr Steven Kymes, Washington University School of Medicine Department of Ophthalmology and Visual Sciences, 660 South Euclid, Campus Box 8096, Saint Louis, MO 63116 , USA; kymes@vrcc.wustl.edu

doi: 10.1136/bjo.2004.063784

Accepted for publication 3 December 2004 


\section{References}

1 Brown MM, Brown GC. Value based medicine: let's get it right. $\mathrm{Br} J$ Ophthalmol 2004:88:979.

2 Krahn MD, Ritvo P, Irvine J, et al. Patient and community preferences for outcomes in prostate cancer: implications for clinical policy. Medical Care 2003:41:153-64.

3 Gold MR, Siegel JE, Russell LB, et al. Costeffectiveness in health and medicine, 1st ed. New York: Oxford University Press, 1996.

4 Mangione CM, Lee PP, Gutierriez PR, et al. Development of the 25-Item National Eye Institute Visual Function Questionnaire. Arch Ophthalmol 2001;119:1050-8.

5 Salomon JA, Murray CJL. A multi-method approach to measuring health-state valuations. Health Economics 2004;13:281-90.

6 Jampel HD. Glaucoma patients' assessment of their visual function and quality of life. Trans Am Ophthamol Soc 2001;99:301-17.

\section{Authors' reply}

We thank Drs Kymes and Frick for their excellent letter regarding utility analysis as a health related quality of life instrument. We agree that the use of primarily function based quality of life instruments such as the NEIVFQ-25 may result in missing many important variables in the quality of life arena, as well as limit applicability across all diseases. In contrast, preference based quality of life instruments, such as utility analysis, are applicable across all diseases and encompass all variables that comprise quality of life, as well as the weighting of those variables. Of great additional importance is the fact that preference based instruments can be used in healthcare economic analyses, especially utility analysis, while most function based instruments have not been successfully used. $^{12}$

Concerning the use of time trade-off and standard gamble utility analysis, we have found that the time trade-off methodology is easier for patients to comprehend and also is more sensitive to milder health states since there is risk aversion to the consequence of immediate death associated with the standard gamble variant. ${ }^{12}$ Froberg and Kane ${ }^{3}$ have also shown that the time trade-off method of utility has greater test-retest reliability, intra-rater reliability and interrater reliability than standard gamble methodology. In our experience, time trade-off utilities generally demonstrate better construct validity ${ }^{1}$ and a wider range between pre-intervention and post-intervention values than standard gamble utilities, thus resulting in more favourable cost utility analysis, rather then less favourable analyses.

With regard to quality of life respondents, we remain firm in our adherence to the fact that a basic pillar of value based medicine is the use of utility values obtained from respondents with a health state in question. ${ }^{12}$ We have found that utility value diminution in patients who actually have age related macular degeneration ranges from $103 \%$ to $750 \%$ greater than the decrement estimated by treating ophthalmologists for the same condition. ${ }^{45}$ This has been noted as well for non-ophthalmological health states. ${ }^{6}$

We respectfully disagree that community utility values generally overestimate the degree to which a disease decreases quality of life. In contrast, we and others ${ }^{4-9}$ have noted that community and provider participants asked to evaluate the quality of life associated with a health state using utility value analysis generally underestimate the decrement in quality of life compared to patients with that health state. In essence, patients who have lived with a health state are those best able to ascertain the quality of life associated with that health state. And it is usually worse than others imagine.

In conclusion, we thank Kymes and Frick for their interest and comments and look forward to additional awareness in the arena of value based medicine. As increasing numbers of those who allocate healthcare resources become aware that value based medicine allows for higher quality care (by incorporating quality of life parameters that evidence based primary clinical trials often ignore) and the most efficient use of resources, it will have a considerably greater role in the delivery of cost effective, quality healthcare. When that takes place, all will benefit.

\section{Brown, G C Brown \\ Center for Value-Based Medicine, PO Box 335 Flourtown, PA 19031-1404, USA}

Correspondence to: Dr Melissa Brown, Center for Value-Based Medicine, PO Box 335, Flourtown, PA 19031-1404, USA; lissa1011@aol.com

doi: 10.1136/bjo.2004.063792

Accepted for publication 3 December 2004

\section{References}

1 Brown MM, Brown GC, Sharma, S. Evidencebased to value-based medicine. Atlanta, GA: AMA Press, 2005

2 Brown MM, Brown GC, Sharma S, et al. Health care economic analyses and value-based medicine. Surv Ophthalmol 2003;48:204-23.

3 Froberg DG, Kane RL. Methodology for measuring health state preferences. II. Scaling methods. J Clin Epidemiol 1989:42:459-71.

4 Brown GC, Brown MM, Sharma S. Difference between ophthalmologist and patient perceptions of quality-of-life associated with age-related macular degeneration. Can J Ophthalmol 2000;35:27-32.

5 Brown GC, Brown MM, Sharma S, et al. The burden of age-related macular degeneration. A value-based analysis. Curr Opin Ophthalmol, (in press).

6 Fryback DG, Dasbach EJ, Klein R, et al. The Beaver Dam Outcomes Study: initial catalog of health-state quality factors. Med Dec Making 1993;13:89-102.

7 Stein JD, Brown MM, Brown GC, et al. Quality of life with macular degeneration. Perceptions of patients, clinicians and community members. Br J Ophthalmol 2003;87:8-12.

8 Landy J, Stein JD, Brown GC, et al. Patient community and clinician perceptions of the quality of life associated with diabetes mellitus. Medical Science Monitor 2002;8:543-8.

9 Sharma S, Brown GC, Brown MM, et al. Validity of the time trade-off and standard gamble methods of utility assessment in retinal patients. Br J Ophthalmol 2002;86:493-6.

\section{Cystoid macular oedema with trypan blue use}

We read with interest the article by Gouws et $\mathrm{al}^{1}$ on the apparent increased incidence of cystoid macular oedema (CMO) in phacoemulsification patients when trypan blue was used to stain the anterior capsule.

Trypan blue has been commonly used in both anterior and posterior segment surgeries. ${ }^{2-4}$ If trypan blue does cause macular toxicity, its risks should theoretically be higher when used in posterior segment surgeries. However, studies on the use of trypan blue, both in the anterior ${ }^{23}$ and posterior $^{45}$ segments, did not show apparent toxicity.

Thus, it would be appreciated if the authors could clarify whether other potential confounders were assessed in their study, including: (1) other causes of CMO such as diabetes, uveitis, and prostaglandin use; (2) operating time since phototoxicity from the operative microscope ${ }^{6}$ is a risk factor for CMO development. It appears that only operations for patients in group B were performed by one surgeon, if operations for patients in group A (with trypan blue use) were done by trainees, the operative time is expected to be longer; (3) whether all patients received a fundus examination with dilated pupil after the operation. If these were only performed in patients with suboptimal visual acuities, the incidence of CMO may be underestimated.

Finally, we concur with the authors' view that we should try all means in terms of minimising any theoretical toxicities of trypan blue. It is our routine to actively remove trypan blue with the bimanual irrigation aspiration system as soon as the anterior capsule has been stained. It is very effective and the potential toxicities may be reduced.

H K L Yuen, R F Lam, D S C Lam The Chinese University of Hong Kong, Hong Kong

Correspondence to: Dennis S C Lam, The Chinese University of Hong Kong, Hong Kong; dennislam@ cuhk.edu.hk

doi: 10.1136/bjo.2005.066035

Accepted for publication 4 January 2005

\section{References}

1 Gouws P, Merriman M, Goethals S, et al. Cystoid macular oedema with trypan blue use. Br J Ophthalmol 2004;88:1348-9.

2 Melles GR, de Waard PW, Pameyer JH, et al Trypan blue capsule staining to visualize the capsulorhexis in cataract surgery. J Cataract Refract Surg 1999;25:7-9.

3 Dada VK, Sharma N, Sudan R, et al. Anterior capsule staining for capsulorhexis in cases of white cataract: comparative clinical study. J Cataract Refract Surg 2004:30:326-33.

4 Feron EJ, Veckeneer M, Parys-Van Ginderdeuren R, et al. Trypan blue staining of epiretinal membranes in proliferative vitreoretinopathy. Arch Ophthalmol 2002; 120:141-4.

5 Li K, Wong D, Hiscott P, et al. Trypan blue staining of internal limiting membrane and epiretinal membrane during vitrectomy: visual results and histopathological findings. Br J Ophthalmol 2003;87:216-9.

6 Donzis PB, DeBartolo DF, Lewen RM, et al. Lightinduced maculopathy and cystoid macular edema. J Cataract Refract Surg 1988;14:84-5.

\section{Authors' reply}

We thank Lam et al for their interest. In response to their comments, as stated in the article and demonstrated in figures $\mathrm{IB}$ and $\mathrm{C}$, the effect persists when co-morbidity such as diabetes is removed.

Both groups' surgery was performed by the same surgeon who did not have juniors attached to the list.

Not all patients had dilated fundus examination postoperatively. Clinically significant cystoid macular oedema (CMO) is unlikely in patients with visual acuities of 6/12 or better, although subclinical CMO can be demonstrated in up to $20 \%$ with fluorescein angiography. 
This retrospective study on a unique cohort of patients provided us with the opportunity to demonstrate a potential side effect with the use of trypan blue. A prospective trial is required to control for all the variables and confirm or refute our findings.

P Gouws, P Simcock Conquest Hospital, Hastings, UK

Correspondence to: Peter Simcock, West of England Eye Unit, Royal Deom and Exeter Hospital, Exeter EX2 5DW, UK; psimcock@hotmail.com

doi: 10.1136/bjo.2004.069765

Accepted for publication 23 February 2005

\section{Reference}

1 Ursell PG, Spalton DJ, Whitcup SM, et al. Cystoid macular edema after phacoemulsification: relationship to blood-aqueous barrier damage and visual acuity. J Cataract Refract Surg 1999;25:1492-7.

\section{BOOK REVIEW}

\section{The History of Moorfields Eye Hospital, Volume III}

Ed Peter K Leaver. London: Royal Society of Medicine Press Ltd, 2004, pp 360; £30. ISBN 1-85315-580-2.

Like John Mortimer's book of a similar title this third volume of the history of Moorfields Eye Hospital is an affectionate but critical look back at the hospital that has been a major influence in many ophthalmologists' training and subsequent practice. The volume is written in a positive upbeat style but also describes some of the faults and difficulties that have beset it in the past four decades. In a complex organisation such as a hospital there are inevitable inefficiencies and problems with personalities but the author has wisely stuck to the facts and has plotted the course of the management of the hospital in a very readable way; he has sensibly avoided petty confrontations and offers a lucid outline of the course of Britain's flagship ophthalmic hospital.

The two previous histories of Moorfields described times past when ophthalmic practice changed only gradually and political upheaval was minor. The current author has been in the unique position of being involved with Moorfields throughout the 40 years he describes. Given the turmoil, both professional and managerial, that has engulfed the delivery of health care during this period he was fortunate that many of the individuals involved with the hospital were available for interview, thus providing first hand accounts of the good and bad times that affected the hospital. The various chapters outline lucidly the clinical and political changes of the time; Moorfields represents in microcosm all the influences to which NHS consultants of all disciplines have been subjected. One special feature of the period described is that it also covers the first 40 years following the foundation of the Institute of Ophthalmology and the not always easy relationship between the hospital and the institute is recorded both openly and tactfully.

The book comprises a number of chapters outlining the various aspects of the hospital development-for example, clinical, managerial, financial, etc. The first chapter is an overview involving all aspects of the hospital during the 40 years from 1963 to 2003. It provides a concise synopsis of all the forces bearing on the hospital; not only clinical but also in terms of research, teaching, and political upheaval. Indeed, for those younger ophthalmologists entering the profession at the present time this chapter gives a concise overview of those political influences that have shaped the lives of the NHS and its staff during recent decades.

As the author points out in his preface the subsequent chapters take up the issues raised in the first chapter and analyse them in more detail. If one, therefore, picks up the book and reads it cover to cover there is a strong repetitive element but it was not really the author's intention that the book should be necessarily read in this way. Each of the later chapters is written in a stand alone fashion dealing with clinical progress, academic development, research, management, and finance so that some repetition is inevitable. The major characters in the story of Moorfields development are given due weight; particularly Professor Barrie Jones, under whose influence Moorfields progressed from a rather slow moving organisation to the establishment of all the subspecialist services we know today.

Apart from rather a large number of nautical metaphors such as "calm waters," "stormy seas," and a few petty errors of detail, such as dates, this volume is a good read, particularly if approached as the author intended. He himself has made major contributions to the standing of Moorfields Eye Hospital and the book is written in the typically clear and polished style, reminiscent of his own scientific contributions.

R Grey

Bristol Eye Hospital, Lower Maudlin Street, Bristol BSI 2LX, UK; linda.clayton@ubht.swest.nhs.uk

\section{NOTICES}

\section{Worldwide clinical trials for new technique for early detection of eye disease}

A unique new non-invasive technique for high resolution optical imaging of the eye is receiving global acclaim. By combining two high-resolution imaging technologies, the new technique provides doctors with 3-D images of the retina, macula and the optic nerve.
For more information, contact the Media Office on $01227823581 / 823100$ or email MediaOffice@kent.ac.uk News releases can also be found at: http://www.kent.ac.uk/news

\section{Trachoma control}

The latest issue of Community Eye Health (No 52) discusses new developments in the control of trachoma. For further information please contact: Journal of Community Eye Health, International Resource Centre, International Centre for Eye Health, Department of Infectious and Tropical Diseases, London School of Hygiene and Tropical Medicine, Keppel Street, London WCIE 7HT, UK (tel: +44 (0)207612 7964; email: Anita.Shah@ lshtm.ac.uk; online edition: www.jceh.co. uk). Annual subscription (4 issues) UK $£ 28$ / US\$45. Free to developing country applicants.

\section{EVER 2005 meeting}

This will take place on 5-8 October 2005 in Vilamoura, Portugal. For further details please contact: Christy Lacroix, EVER Secretary, Kapucijnenover 33, B-3000 Leuven, Belgium (tel: +32 (0)16 233 849; fax +32 (0) $16 \quad 234$ 097; email:ever@ skynet.be).

\section{World Ophthalmology Congress 2006 - Brazil}

The World Ophthalmology Congress (which is replacing the International Congress of Ophthalmology) is meeting in February 2006 in Brazil.

For further information on the congress and committees, scientific program and coordinators of different areas are available at the congress website www.ophthalmology2006. com.br

\section{CORRECTIONS}

doi: 10.1136/bjo.2005.42556corrl

In the letter entitled, Norrie disease and peripheral venous insufficiency $(B r \quad J$ Ophthalmol 2004;88:1475) the ordering of the authors was incorrect. The correct order is Michaelides M, Luthert PJ, Cooling R, Firth $\mathrm{H}$, Moore AT. The journal apologises for this error.

doi: 10.1136/bjo.2005.58032corrl

Owing to an author error the name of one of the authors of the paper entitled, Long term effect on IOP of a stainless steel glaucoma drainage implant (Ex-PRESS) in combined surgery with phacoemulsification, which appeared in the April issue of the journal (Br J Ophthalmol 2005;89:423-9) was omitted (S Gandolfi). The author list should be C Traverso, F De Feo, A Messas-Kapal, $\mathrm{P}$ Denis, S Levartovsky, E Sellem, F Badalà, Z Zagorski, A Bron, S Gandolfi, M Belkin. $\mathrm{S}$ Gandolfi is at the Clinica Oculistica, University of Parma, Italy. 